Cochrane Database of Systematic Reviews

\title{
Opioids for cancer pain - an overview of Cochrane reviews (Review)
}

Wiffen PJ, Wee B, Derry S, Bell RF, Moore RA

Wiffen PJ, Wee B, Derry S, Bell RF, Moore RA.

Opioids for cancer pain - an overview of Cochrane reviews.

Cochrane Database of Systematic Reviews 2017, Issue 7. Art. No.: CD012592.

DOI: 10.1002/14651858.CD012592.pub2.

www.cochranelibrary.com 
TABLE OF CONTENTS

ABSTRACT 1

PLAIN LANGUAGE SUMMARY

BACKGROUND

Figure 1.

OBJECTIVES

METHODS

RESULTS

DISCUSSION

AUTHORS' CONCLUSIONS

ACKNOWLEDGEMENTS

REFERENCES

APPENDICES

WHAT'S NEW

HISTORY

CONTRIBUTIONS OF AUTHORS

DECLARATIONS OF INTEREST

SOURCES OF SUPPORT

NOTES

INDEX TERMS 
[Overview of Reviews]

\title{
Opioids for cancer pain - an overview of Cochrane reviews
}

Philip J Wiffen ${ }^{1}$, Bee Wee ${ }^{2}$, Sheena Derry ${ }^{3}$, Rae Frances Bell ${ }^{4}$, R Andrew Moore ${ }^{5}$

${ }^{1}$ Thame, UK. ${ }^{2}$ Nuffield Department of Medicine and Sir Michael Sobell House, Churchill Hospital, Oxford, UK. ${ }^{3}$ Oxford, UK. ${ }^{4}$ Regional Centre of Excellence in Palliative Care, Haukeland University Hospital, Bergen, Norway. ${ }^{5}$ Plymouth, UK

Contact: Philip J Wiffen, Thame, UK. pwiffen@oxfordsrs.org.uk.

Editorial group: Cochrane Pain, Palliative and Supportive Care Group.

Publication status and date: Stable (no update expected for reasons given in 'What's new'), published in Issue 2, 2020.

Citation: Wiffen PJ, Wee B, Derry S, Bell RF, Moore RA. Opioids for cancer pain - an overview of Cochrane reviews. Cochrane Database of Systematic Reviews 2017, Issue 7. Art. No.: CD012592. DOI: 10.1002/14651858.CD012592.pub2.

Copyright $@ 2020$ The Cochrane Collaboration. Published by John Wiley \& Sons, Ltd.

\begin{abstract}
A B S T R A C T
Background

Pain is a common symptom with cancer, and $30 \%$ to $50 \%$ of all people with cancer will experience moderate to severe pain that can have a major negative impact on their quality of life. Opioid (morphine-like) drugs are commonly used to treat moderate or severe cancer pain, and are recommended for this purpose in the World Health Organization (WHO) pain treatment ladder. The most commonly-used opioid drugs are buprenorphine, codeine, fentanyl, hydrocodone, hydromorphone, methadone, morphine, oxycodone, tramadol, and tapentadol.
\end{abstract}

\section{Objectives}

To provide an overview of the analgesic efficacy of opioids in cancer pain, and to report on adverse events associated with their use.

\section{Methods}

We identified systematic reviews examining any opioid for cancer pain published to 4 May 2017 in the Cochrane Database of Systematic Reviews in the Cochrane Library. The primary outcomes were no or mild pain within 14 days of starting treatment, withdrawals due to adverse events, and serious adverse events.

\section{Main results}

We included nine reviews with 152 included studies and 13,524 participants, but because some studies appeared in more than one review the number of unique studies and participants was smaller than this. Most participants had moderate or severe pain associated with a range of different types of cancer. Studies in the reviews typically compared one type of opioid or formulation with either a different formulation of the same opioid, or a different opioid; few included a placebo control. Typically the reviews titrated dose to effect, a balance between pain relief and adverse events. Various routes of administration of opioids were considered in the reviews; oral with most opioids, but transdermal administration with fentanyl, and buprenorphine. No review included studies of subcutaneous opioid administration. Pain outcomes reported were varied and inconsistent. The average size of included studies varied considerably between reviews: studies of older opioids, such as codeine, morphine, and methadone, had low average study sizes while those involving newer drugs tended to have larger study sizes.

Six reviews reported a GRADE assessment (buprenorphine, codeine, hydromorphone, methadone, oxycodone, and tramadol), but not necessarily for all comparisons or outcomes. No comparative analyses were possible because there was no consistent placebo or active control. Cohort outcomes for opioids are therefore reported, as absolute numbers or percentages, or both.

Reviews on buprenorphine, codeine with or without paracetamol, hydromorphone, methadone, tramadol with or without paracetamol, tapentadol, and oxycodone did not have information about the primary outcome of mild or no pain at 14 days, although that on oxycodone indicated that average pain scores were within that range. Two reviews, on oral morphine and transdermal fentanyl, reported that $96 \%$ of 850 participants achieved that goal. 
Adverse event withdrawal was reported by five reviews, at rates of between $6 \%$ and $19 \%$. Participants with at least one adverse event were reported by three reviews, at rates of between $11 \%$ and $77 \%$.

Our GRADE assessment of evidence quality was very low for all outcomes, because many studies in the reviews were at high risk of bias from several sources, including small study size.

\section{Authors' conclusions}

The amount and quality of evidence around the use of opioids for treating cancer pain is disappointingly low, although the evidence we have indicates that around 19 out of 20 people with moderate or severe pain who are given opioids and can tolerate them should have that pain reduced to mild or no pain within 14 days. This accords with the clinical experience in treating many people with cancer pain, but overstates to some extent the effectiveness found for the WHO pain ladder. Most people will experience adverse events, and help may be needed to manage the more common undesirable adverse effects such as constipation and nausea. Perhaps between 1 in 10 and 2 in 10 people treated with opioids will find these adverse events intolerable, leading to a change in treatment.

\section{PLAIN LANGUAGE SUMMARY}

\section{Morphine-like drugs for cancer pain}

\section{Bottom line}

In about 19 of 20 people with moderate to severe pain from cancer, morphine-like drugs (opioids) can probably reduce pain to mild or no pain within 14 days if they can tolerate the side effects. Most people will have side effects, and about 1 in 10 to 2 in 10 will need to change their treatment because of side effects.

\section{Background}

One person in two or three who gets cancer will suffer from pain that becomes moderate or severe in intensity. The pain tends to get worse as the cancer progresses. Morphine taken by mouth has been used since the 1950s for controlling cancer pain. In 1986 the World Health Organization (WHO) recommended taking morphine-like drugs for moderate to severe pain from cancer. A number of different drugs are available, some taken by mouth, but others applied in stick-on patches.

\section{Study characteristics}

In this overview of Cochrane Reviews we examined all the evidence on how well morphine-like drugs worked, mostly when taken by mouth or through a skin patch, how many people had side effects, and how severe or troublesome those side effects were - for example, whether they caused participants to stop taking their medicines.

In May 2017, we found nine reviews with 152 included studies and 13,524 participants. The studies were often small, and compared many different preparations. They used different study designs and different ways of showing their pain results. Outcomes of importance to people with cancer pain were often not reported.

\section{Key findings}

For two drugs (morphine by mouth and fentanyl patches) more than 19 in 20 people had pain that went from moderate or severe before taking morphine-like drugs, to pain that was no worse than mild within 14 days if they can tolerate the side effects. Most people taking a morphine-like drug had at least one side effect. Only about 1 person in 10 to 2 people in 10 stopped taking it because of side effects. The most common side effects were constipation, and nausea and vomiting.

\section{Quality of the evidence}

At one level these are encouraging results, and generally agree with surveys of how well the WHO advice works in cancer pain. On another level, the quality of studies in the reviews was generally poor. We would like better study design, and especially better study reporting, which should include the outcome of pain reduced to a level where people with cancer can cope with it (no pain or mild pain).

We found that the Cochrane Reviews were of high quality.

We rated the quality of the evidence from studies using four levels: very low, low, moderate, or high. Very low quality evidence means that we are very uncertain about the results. High-quality evidence means that we are very confident in the results. We rated the evidence in the reviews as very low quality. 


\section{B A C K G R O U N D}

\section{Description of the condition}

Cancers are among the leading causes of morbidity and mortality worldwide, with about 14 million new cases and over eight million deaths annually - approximately $13 \%$ of deaths worldwide (IARC 2012; Stewart 2014). Globally, 32 million people are living with cancer. In the UK alone in 2014, there were around 350,000 new cases of cancer annually, with around $50 \%$ of people surviving for 10 years or more after diagnosis (CRUK 2014).

Cancer pain is perhaps one of the most feared symptoms associated with the disease. Pain may be the first symptom to cause someone to seek medical advice that leads to a diagnosis of cancer, and $30 \%$ to $50 \%$ of all people with cancer will experience moderate to severe pain (Portenoy 1999). Pain can occur at any time as the disease progresses but the frequency and intensity of pain tends to increase as the cancer advances (Portenoy 1999; van den Beuken-van Everdingen 2016). A systematic review published in 2016 has shown that approximately $40 \%$ of patients suffered pain after curative treatment, $55 \%$ during cancer treatment, and $66 \%$ in advanced disease (van den Beuken-van Everdingen 2016).

Central to cancer pain, and always a consideration when evaluating evidence for treatment, is the recognition that cancer pain is rarely of uniform intensity. It can be episodic (related to or independent from inciting events/incident pain), with no pain in between or with lesser background pain. The term 'breakthrough pain' is debated (Mercadante 2016); there is a literature on opioids for breakthrough pain, though that is not a subject for this overview. Schemes used for titration or initiation of pain relief differ from those used for maintenance; these are considered separately in cancer pain guidelines, and are not specifically the target of this review.

Pain related to cancer is described as distressing or intolerable by more than one third of patients (Breivik 2009; van den Beuken-van Everdingen 2016). For those people with advanced cancer, some $75 \%$ to $90 \%$ will experience pain that has a major impact on daily living (van den Beuken-van Everdingen 2016). Pain had a significant negative correlation with quality of life in people with cancer, for example patients in China, Palestine, and Japan (Deng 2012; Dreidi 2016; Mikan 2016), as is true generally with pain (Moore 2014). Significant relief of pain to a level equivalent to no pain or only mild pain is generally regarded as an important target for most people with pain (Moore 2013).

Cancer pain can be the result of the cancer itself, interventions to treat the cancer, and sometimes other underlying pains. Prevalence is also linked to cancer type, with head and neck cancer showing the highest prevalence. Age also has an impact, with younger patients experiencing more pain (Prommer 2015). For the purposes of this overview review we will focus on the use of opioids for the treatment of pain associated with active cancer in adults where the pain is thought to be associated with the cancer or its treatment.

Separate reviews on paracetamol and NSAIDs (Derry 2017; Wiffen 2017a), and a separate review of opioids in cancer pain in children, are underway (Wiffen 2017b).

\section{Description of the interventions}

Opioid analgesics, including codeine, play a significant role in major guidelines associated with the management of pain for patients diagnosed with cancer (Caraceni 2012; Jacox 1994; Miaskowski 2005; NICE 2016; Ripamonti 2012a; SIGN 2008; WHO 1996).

Opioids are used to manage moderate to severe pain. Morphine is the oldest drug in the class of opioids and is still generally considered to be the gold standard. Many other opioids are comparable to morphine in terms of analgesia and also adverse effects. Codeine is considerably less potent than morphine and recommended for mild to moderate cancer pain. The majority of opioids are administered orally, often in the form of modifiedrelease formulations to reduce dosing to once or twice daily. Rectal administration is also possible. Fentanyl and buprenorphine can also be administered by transdermal patch. Some opioids are suitable for parenteral administration, but this review will not specifically consider this route of administration.

Over 16 million prescriptions for potent opioids are prescribed in primary care and dispensed in England each year (PCA 2016), though only about $13 \%$ are for cancer pain (Zin 2014). The numbers of prescriptions (excluding codeine which is widely used in mild to moderate pain) are as follows: tramadol 7.3 million, morphine 4.8 million, buprenorphine 2.1 million, oxycodone 1.5 million, fentanyl 1.2 million, tapentadol 115,000 , methadone 56,000 and hydromorphone 9000 . It should be noted that tramadol and buprenorphine are widely used for treatments other than cancer pain. The highest proportion of cancer patients was prescribed low opioid doses (oral morphine equivalents $\leq 50 \mathrm{mg} /$ day; $40 \%$ ), followed by the dose ranks of $51 \mathrm{mg} /$ day to $100 \mathrm{mg} /$ day (28\%), 101 $\mathrm{mg} /$ day to $200 \mathrm{mg} /$ day (19\%), and more than $200 \mathrm{mg} /$ day (12\%) (Zin 2014).

Morphine and codeine are the two opioids included in the World Health Organization (WHO) essential drugs list (WHO 2011); other opioids are generally similar, but have differences in potency, lipophilicity (the ability of a chemical compound to dissolve in fats, oils, lipids), and routes of administration. These can be important in certain circumstances. All opioids were eligible for inclusion in this overview, but details are given for morphine and codeine as examples in this background description.

\section{Morphine}

Morphine in one form or another has been available for centuries, and appeared in Pliny's Historia Naturalis (77 AD) as opium, the resin derived from poppy sap. Morphine was extracted from opium in 1803 and named as such by Sertürner, a German pharmacist from Einbeck, in 1817 (Rey 1993). Oral morphine was first recommended for the treatment of cancer pain in England in the 1950s. This was often in the form of the so-called 'Brompton cocktail', containing cocaine and alcohol in addition to morphine or diamorphine. Treatment moved towards oral morphine alone as morphine demonstrated effective pain relief without the side effects linked to the 'cocktail'.

Following the publication of WHO guidelines in the mid-1980s, the oral administration of aqueous morphine solution every four hours by the clock became commonplace for moderate to severe cancer pain (WHO 1986). Morphine in a modified-release tablet was first marketed around the same time, allowing the dosage interval to be extended to 12 hours. 
The wide range of formulations and dosages allows great flexibility in the management of severe pain (Grahame-Smith 2002). Potent opioid analgesics are particularly indicated for the relief of pain in malignant disease and often have the additional very useful actions of relieving anxiety, producing drowsiness, and allowing sleep (Grahame-Smith 2002). However, all opioid analgesics have the potential to produce adverse events: respiratory depression, nausea and vomiting, constipation, increased pain sensitivity (hyperalgesia), excessive drowsiness, and itching; and morphine can also produce memory loss, nightmares and myoclonic jerks. During chronic opioid therapy, larger doses may be required to sustain the analgesic effect (tolerance) and people can be at risk of opioid withdrawal syndrome upon sudden cessation of the opioid or administration of an antagonist (physiological dependence).

This overview will not consider evidence relating to opioid combinations, for which it is known that there is only a small amount of weak evidence (Fallon 2011).

\section{Codeine}

Guidelines generally recommend codeine as an analgesic for moderate pain or for situations where simple analgesics (for example, nonsteroidal anti-inflammatory drugs (NSAIDs) or paracetamol) alone are ineffective or provide suboptimal analgesia. Codeine is the most widely used, naturally occurring narcotic in medical treatment in the world (Opiates 2013). Codeine can also be synthesised from morphine. It is most commonly administered by mouth (as tablets or syrup), but is also available for intramuscular and subcutaneous injections, and in some countries as suppositories. In many countries it is a controlled substance.

In some clinical guidelines, codeine is referred to as a 'weak' opioid analgesic. Codeine and tramadol are defined as step II opioids on the WHO analgesic ladder. The role and utility of step II opioids in cancer pain are controversial (Ripamonti 2012b), and there is currently a discussion as to whether step II opioids should be omitted from the ladder since low doses of step III opioids are equally effective - or in the case of 'poor metabolisers', more effective. The European Association for Palliative Care currently recommends both options (Caraceni 2012).

\section{How the intervention might work}

Morphine is known to bind to opioid receptors to produce pain relief (Mandal 2013). Three different receptors have been identified.

1. Mu receptors (subdivided into $\mu 1, \mu 2$, and $\mu 3$ ). These are found in the brainstem and the thalamus. Activation can result in pain relief, sedation, and euphoria, and can also lead to respiratory depression, constipation, and physical dependence.

2. Kappa receptor. This is found in the limbic system, the brain stem, and spinal cord. Activation can result in pain relief, sedation, breathlessness, dysphoria (a state of unease or dissatisfaction), and dependence.

3. Delta receptor. This is found in the brain, spinal cord, and digestive tract. Activation can result in analgesic as well as antidepressant effects. It can also lead to respiratory depression.

The majority of opioids are metabolised by the liver and this can lead to poor or extensive metabolisers, which affects the analgesia

Opioids for cancer pain - an overview of Cochrane reviews (Review)

Copyright (c) 2020 The Cochrane Collaboration. Published by John Wiley \& Sons, Ltd. experienced by users. The most affected drugs are codeine and tramadol.

\section{Morphine}

The analgesic effect of morphine is due to its action on the mu opioid receptor. Morphine is metabolised in the liver and brain, the predominant metabolites being morphine-3-glucuronide and morphine-6-glucuronide. The total production of morphine-3glucuronide is approximately five times higher than that of morphine-6-glucuronide. Morphine-3-glucuronide has low potency at the mu receptor and is considered to be inactive in humans, while morphine-6-glucuronide is a mu receptor agonist with analgesic effect and is more potent than morphine (Paul 1989; Wittwer 2006).

Therapeutic concentrations of morphine and morphine-6glucuronide have been suggested (Faura 1996), though a systematic review of factors affecting the ratios of morphine and its major metabolites shows some additional complexities (Faura 1998). Peak plasma concentrations after oral administration depend on the formulation used (Collins 1998). Renal failure can lead to reduced excretion of morphine-6-glucuronide and build-up in the body, necessitating dose adjustments (Ball 1985; Sear 1985; Sear 1989), though alternative drugs such as fentanyl or oxycodone are often used instead where renal problems may be present, since these alternatives to morphine are far less dependent on the kidneys for excretion.

\section{Codeine}

Codeine is a prodrug that is metabolised to morphine in the liver. In most people, $5 \%$ to $10 \%$ of codeine is converted to morphine; a $30 \mathrm{mg}$ dose of codeine is considered equivalent to a $3 \mathrm{mg}$ dose of morphine. The ability to metabolise codeine varies between individuals. Some (up to $10 \%$ of white people, $2 \%$ of Asians, and $1 \%$ of Arabs) are 'poor metabolisers' with low rates of conversion (Cascorbi 2003), and in these people codeine is a relatively ineffective analgesic. At the other extreme, a few individuals are 'extensive metabolisers' with high rates of conversion, and this puts them at increased risk of toxicity from standard doses. There are rare case reports of deaths attributed to ultrarapid metabolism of codeine administered at recommended doses (Ciszkowski 2009; Madadi 2007).

A number of medications can interfere with the enzymes that catalyse the metabolism of codeine, and by increasing or decreasing the extent of conversion they can change the analgesic effect. For example the selective serotonin reuptake inhibitors (SSRIs) fluoxetine and paroxetine (used for the treatment of depression which may present as a co-morbidity along with malignant disease), as well as the serotonin and noradrenaline reuptake inhibitor duloxetine (which may be used for pain management), reduce conversion; and other drugs, such as rifampicin and dexamethasone, increase it.

\section{Why it is important to do this overview}

The goal of treatment of cancer pain is to minimise pain in a relatively short period while minimising adverse event severity (Figure 1). Measurement of pain and assessment of adverse event severity and impact are key to this. Opioids are an important part of managing cancer pain. In many countries, strong opioids such as morphine are severely restricted, if available at all. This leaves many people with cancer at risk of severe pain and suffering. 
Figure 1.

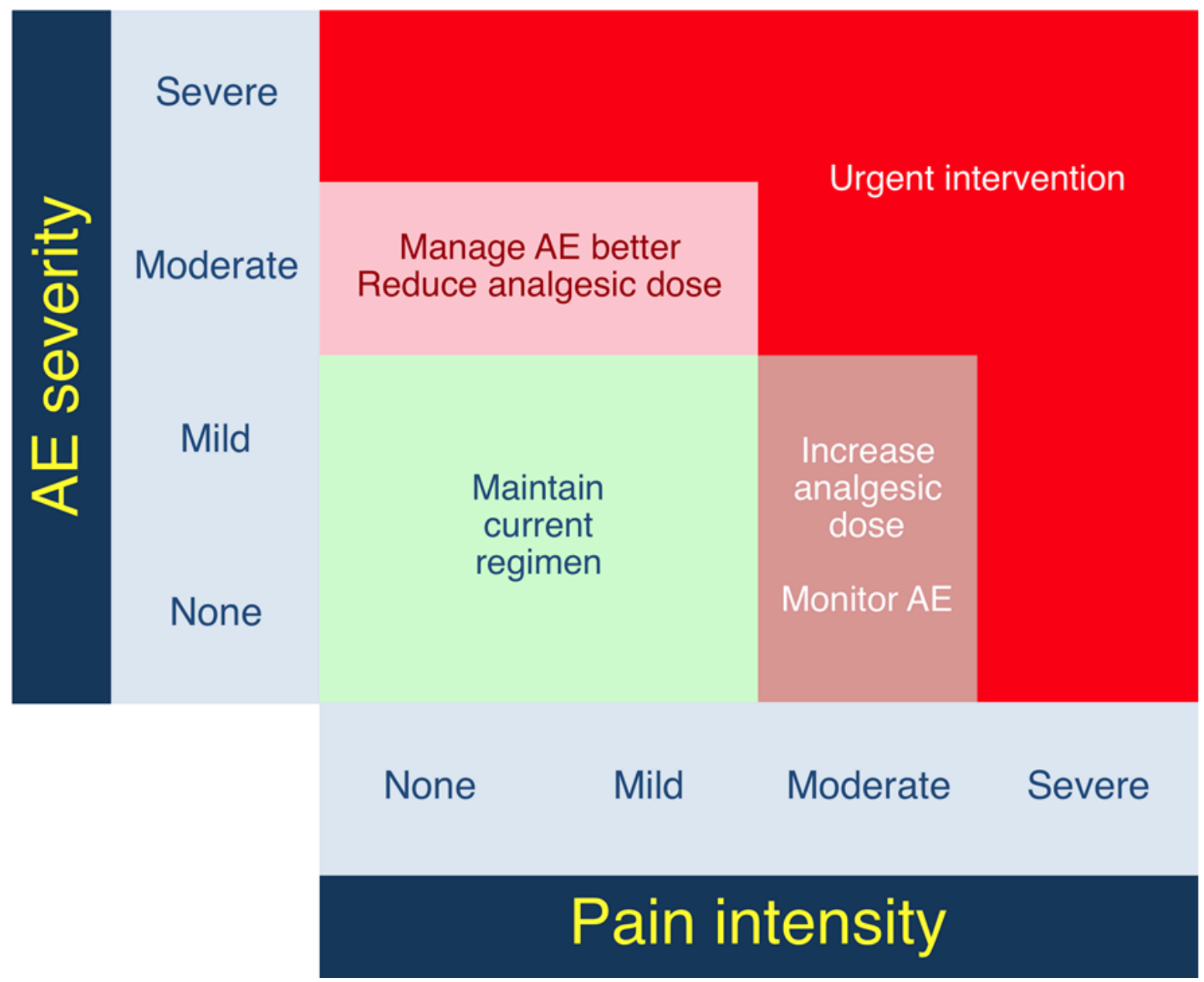

Morphine has long been considered the preferred choice of opioid. It is widely, though still not universally, available across the world, is comparatively inexpensive, and is effective orally. It is listed in the WHO essential medicines list (WHO 2011). This overview of Cochrane Reviews is important to determine the effectiveness of morphine compared to other interventions used in cancer pain. Codeine is inexpensive and has a long track record of use since the late 1800 s. However, there is an ongoing controversy as to whether there is a place for step II opioids such as tramadol and codeine in the treatment of cancer pain.

This overview provides a summary of the evidence for the majority of opioid medicines available internationally and covers those on the WHO essential medicines list, namely codeine and morphine. This review will inform policy makers such as the WHO on the evidence for analgesic efficacy and adverse effects of opioids to treat cancer-related pain.

There are also fears regarding implementing and prescribing opioids. Clinicians might be reassured regarding the safety profile and effectiveness of opioids, and that should lead to improved pain management and treatment earlier in cancer, alongside Cochrane Reviews on paracetamol and NSAIDs (Derry 2017; Wiffen 2017a). People with cancer sometimes feel that a prescription of morphine can signify that they are in the last stages of illness.
Reassurance that opioids are not confined to end stage illness could be reassuring.

\section{O B JECTIVES}

To provide an overview of the analgesic efficacy of opioids in cancer pain, and to report on adverse events associated with their use.

\section{METHODS}

\section{Criteria for considering reviews for inclusion}

We included all Cochrane Reviews of randomised, controlled trials (RCTs) of opioid drugs for the treatment of cancer pain in adults.

\section{Search methods for identification of reviews}

We searched the Cochrane Database of Systematic Reviews (in the Cochrane Library) on 4 May 2017. The search strategy is presented in Appendix 1.

\section{Data collection and analysis}

Two review authors independently selected reviews for inclusion, carried out assessments of methodological quality, and extracted data. We resolved any disagreements by discussion, involving a third review author when necessary. 


\section{Selection of reviews}

Included reviews assessed RCTs evaluating the effects of an opioid drug given for relief of moderate to severe cancer pain, compared with placebo or a different active treatment, and provided:

1. details of inclusion and exclusion criteria;

2. details of databases searched and relevant search strategies;

3. patient-reported pain relief; and

4. summary results for at least one desired outcome.

\section{Data extraction and management}

We extracted data from the included reviews using a standard data extraction form, using original study reports only if specific data were missing.

We collected information on:

1. number of included studies and participants;

2. drug, dose, and route of administration;

3. any additional methodological information of potential importance.

We looked for information on risk ratio (RR) and number needed to treat for an additional beneficial outcome (NNT), number needed to treat to prevent an event (NNTp), and number needed to treat for an additional harmful outcome (NNH), or data to calculate these.

\section{Primary outcomes}

1. Proportion of participants reporting no worse than mild pain on treatment by 14 days after start of treatment.

2. Patient Global Impression of Change (PGIC) of much or very much improved.

3. Withdrawals due to adverse events.

These outcomes were also extracted when reported as moderate or substantial improvement according to the relevant Initiative on Methods, Measurement, and Pain Assessment in Clinical Trials (IMMPACT) criteria (Dworkin 2008).

\section{Secondary outcomes}

Description of adverse events including:

1. withdrawals due to lack of efficacy;

2. participants experiencing any adverse event;

3. participants experiencing any serious adverse event, including death. Serious adverse events typically include any untoward medical occurrence or effect that at any dose results in death, is life-threatening, requires hospitalisation or prolongation of existing hospitalisation, results in persistent or significant disability or incapacity, is a congenital anomaly or birth defect, is an 'important medical event' that may jeopardise the patient, or may require an intervention to prevent one of the above characteristics or consequences;

4. specific adverse events, such as thirst, reduced appetite, somnolence and dizziness, as reported.

\section{Assessment of methodological quality of included reviews}

\section{Quality of included reviews}

We assessed each included review to determine if it satisfied the criteria specified in the 'Assessment of Multiple Systematic Reviews' (AMSTAR) measurement tool for rigorous methodological quality (Shea 2007).

Each review was required to:

1. provide an a priori design;

2. carry out duplicate study selection and data extraction;

3. carry out a comprehensive literature search;

4. include published and unpublished studies irrespective of language of publication;

5. provide a list of studies (included and excluded);

6. assess and document the scientific quality of the included studies;

7. use the scientific quality of the included studies appropriately in formulating conclusions;

8. use appropriate methods to combine the findings of studies; and 9. state conflicts of interests.

For each review, we planned to assess the likelihood of publication bias by calculating the number of participants in studies with zero effect $(R R=1)$ that would be needed to give an NNT too high to be clinically relevant (Moore 2008). In this case, we used as a cutoff for clinical relevance an NNT of 10 or above for the outcome of participant-reported pain relief of $30 \%$ or greater. We used this method because statistical tests for presence of publication bias have been shown to be unhelpful (Thornton 2000).

\section{Data synthesis}

We planned to use information on the selected efficacy outcomes to draw up comparisons of analgesic efficacy, using indirect comparisons of different drugs from almost identical clinical trial conditions, with placebo as a common comparator (Glenny 2005; Song 2003). It was known that direct comparison studies were almost completely absent, and probably too small to be of value, but we planned to note any useful observations.

Where the selected efficacy outcomes were not provided in an individual review, we planned to calculate them wherever possible from the data provided. We planned no further data synthesis.

At least 200 participants had to be available for any outcome before we pooled studies (Moore 1998). Where appropriate we planned to use or calculate RR or risk difference (RD) with $95 \%$ confidence intervals (Cls) using a fixed-effect model (Morris 1995). We would have used or calculated NNT and NNH with 95\% Cls using the pooled number of events, following the method devised by Cook and Sackett (Cook 1995). We would have assumed a statistically significant difference from control when the $95 \% \mathrm{Cl}$ of the RR did not include 1 , or 0 for the RD.

In the event, no pooled statistical analysis was possible, and we have reported results for individual studies as absolute numbers or percentages where appropriate. 


\section{Quality of the evidence}

We used the GRADE system to assess the quality of the evidence related to the key outcomes, as appropriate (Appendix 2). Two review authors independently rated the quality of each outcome independently of any GRADE evaluation in the original reports.

We were particularly interested in inconsistency, where point estimates vary widely across studies or $\mathrm{Cl}$ of studies show minimal or no overlap (Guyatt 2011), but there were too few data. Small studies have been shown to overestimate treatment effects, probably because the conduct of small studies is more likely to be less rigorous, allowing critical criteria to be compromised (Dechartres 2013; Nüesch 2010), and large studies often have smaller treatment effects (Dechartres 2014).

In addition, there may be circumstances where the overall rating for a particular outcome needs to be adjusted as recommended by GRADE guidelines (Guyatt 2013a). For example, where there are so few data that the results are highly susceptible to the random play of chance, or if studies use 'last observation carried forward' (LOCF) imputation in circumstances where there are substantial differences in adverse event withdrawals, one can have no confidence in the result, and would need to downgrade the quality of the evidence by three levels, to very low quality. In circumstances where there were no data reported for an outcome, we reported the level of evidence as very low quality (Guyatt 2013b).

We used the following descriptors for levels of evidence (EPOC 2015); substantially different in this context implies a large enough difference that it might affect a decision.

1. High: This research provides a very good indication of the likely effect. The likelihood that the effect will be substantially different is low.

2. Moderate: This research provides a good indication of the likely effect. The likelihood that the effect will be substantially different is moderate.

3. Low: This research provides some indication of the likely effect. However, the likelihood that it will be substantially different is high.

4. Very low: This research does not provide a reliable indication of the likely effect. The likelihood that the effect will be substantially different is very high.

We used the amount and quality of evidence to report results in a hierarchical way, based on the primary outcome of interest, as has been done previously in overview reviews (Moore 2015). We split the available information into five groups, essentially according to the GRADE descriptors.

1. Drugs and doses for which Cochrane Reviews found no information (very low quality evidence).

2. Drugs and doses for which Cochrane Reviews found inadequate information: fewer than 200 participants in comparisons, in at least two studies (very low quality evidence).

3. Drugs and doses for which Cochrane Reviews found evidence of effect, but where results were potentially subject to publication bias. We planned to calculate the number of additional participants needed in studies with zero effect $(R R=1)$ to change the NNT for at least $50 \%$ maximum pain relief to an unacceptably high level (in this case the arbitrary NNT of 10) (Moore 2008). Where this number was less than 400 (equivalent to four studies with 100 participants per comparison, or 50 participants per group), we would consider the results to be susceptible to publication bias and therefore unreliable (lowquality evidence). In the event, there were insufficient data to do this.

4. Drugs and doses for which Cochrane Reviews found no evidence of effect or evidence of no effect: more than 200 participants in comparisons, but where there was no statistically significant difference from placebo (moderate- or high-quality evidence).

5. Drugs and doses for which Cochrane Reviews found evidence of effect, where results were reliable and not subject to potential publication bias (high-quality evidence).

\section{RE S U L T S}

\section{Description of included reviews}

We included nine reviews (Bao 2016; Hadley 2013; Nicholson 2017; Schmidt-Hansen 2015a; Schmidt-Hansen 2015b; Straube 2014; Wiffen 2015; Wiffen 2016; Wiffen 2017c). Summary table A shows the conditions treated, the opioid used, the routes of administration and the numbers of studies and participants included in the reviews.

Most participants had moderate or severe pain associated with a range of different types of cancer. Studies in the reviews typically compared one type of opioid or formulation with either a different formulation of the same opioid, or a different opioid; few included a placebo control. Typically the reviews titrated dose to effect, balancing pain relief with adverse events. Various pain outcomes were used: average pain was reported by some, whilst others reported a $30 \%$ or $50 \%$ reduction in pain, or combinations of different outcomes.

There were 152 included studies and 13,254 participants across all reviews. Some studies were included in more than one review. We excluded one review because it covered only specific adverse effects of certain opioids, did not examine efficacy, and was performed for a specific UK purpose concerning the Liverpool Care Pathway (Wiffen 2014).

Some of the 152 included studies had common active comparators; for example, morphine was used as an active comparator in a number of opioid studies. The number of unique studies was probably closer to 120 . Various routes of administration of opioids were considered in the reviews: oral with most opioids, but transdermal administration only with fentanyl (Hadley 2013), and various routes with buprenorphine (Schmidt-Hansen 2015b).

Several reviews included a small number of studies and participants, but over 1000 participants were involved in studies with buprenorphine, fentanyl, morphine, oxycodone, and tapentadol. The total number of participants in comparisons was over 13,000 , but the number of unique individuals was smaller because some studies included more than one opioid. Most included studies involved head-to-head direct comparisons, and few reported comparisons with placebo.

The average size of included studies varied considerably between reviews. Older opioids, such as codeine, morphine, and methadone, had low average study sizes of 48,68 , and 64 participants respectively. Those involving newer drugs - such as transdermal fentanyl (average 138 participants per study), 
oxycodone (115), and oral tapentadol (257) - tended to involve larger studies. Smaller studies pose problems for interpretation (Fanelli 2017; Moore 1998; Nguyen 2017; Thorlund 2011).
Six reviews reported a GRADE assessment (buprenorphine, codeine, hydromorphone, methadone, oxycodone, and tramadol) but not necessarily for all comparisons or outcomes.

Summary table A: included reviews

\begin{tabular}{|c|c|c|c|}
\hline Reference & Condition treated & Opioid and means of delivery & $\begin{array}{l}\text { Studies/Partici- } \\
\text { pants } \\
\text { (average partici- } \\
\text { pants per study) }\end{array}$ \\
\hline Bao 2016 & $\begin{array}{l}\text { Moderate to severe pain - various can- } \\
\text { cers }\end{array}$ & $\begin{array}{l}\text { Hydromorphone - oral, normal release and } \\
\text { controlled release }\end{array}$ & $4 / 604(151)$ \\
\hline Hadley 2013 & $\begin{array}{l}\text { Severe or chronic cancer pain related } \\
\text { to variety of cancers }\end{array}$ & Fentanyl - transdermal & 9/1244 (138) \\
\hline Nicholson 2017 & $\begin{array}{l}\text { Severe cancer pain due to advanced or } \\
\text { terminal } \\
\text { cancer - variety of cancers }\end{array}$ & Methadone - oral, IM & $6 / 388(64)$ \\
\hline $\begin{array}{l}\text { Schmidt-Hansen } \\
2015 a\end{array}$ & $\begin{array}{l}\text { Cancer-related pain across a range of } \\
\text { malignancies }\end{array}$ & $\begin{array}{l}\text { Oxycodone - oral, normal release and con- } \\
\text { trolled release, IM and IV }\end{array}$ & $23 / 2648(115)$ \\
\hline $\begin{array}{l}\text { Schmidt-Hansen } \\
\text { 2015b }\end{array}$ & $\begin{array}{l}\text { Severe cancer pain related to variety of } \\
\text { cancers }\end{array}$ & $\begin{array}{l}\text { Buprenorphine - sub-lingual, sub-dermal, } \\
\text { transdermal, rectal, epidural, IM, and IV }\end{array}$ & $19 / 1421(75)$ \\
\hline Straube 2014 & $\begin{array}{l}\text { Moderate to severe pain - various can- } \\
\text { cers }\end{array}$ & $\begin{array}{l}\text { Codeine with or without paracetamol - oral, } \\
\text { normal release and controlled release, and } \\
\text { IM }\end{array}$ & $15 / 721(48)$ \\
\hline Wiffen 2015 & $\begin{array}{l}\text { Moderate to severe pain - various can- } \\
\text { cers }\end{array}$ & Tapentadol - oral & $4 / 1029(257)$ \\
\hline Wiffen 2016 & $\begin{array}{l}\text { Moderate to severe pain - various can- } \\
\text { cers }\end{array}$ & $\begin{array}{l}\text { Morphine - oral, instant release and modi- } \\
\text { fied release, rectal, epidural }\end{array}$ & $62 / 4241(68)$ \\
\hline Wiffen 2017c & $\begin{array}{l}\text { Moderate to severe pain - various can- } \\
\text { cers }\end{array}$ & $\begin{array}{l}\text { Tramadol with or without paracetamol - } \\
\text { oral }\end{array}$ & 10/958 (96) \\
\hline
\end{tabular}

\section{Methodological quality of included reviews}

All the reviews met all AMSTAR criteria (Shea 2007). They:

1. had a priori design;

2. performed duplicate study selection and data extraction;

3. had a comprehensive literature search;

4. used published and any unpublished studies, irrespective of language of publication, although not all review authors contacted companies or researchers for unpublished trial data;

5. provided a list of included and excluded studies;

6. provided characteristics of included studies;

7. assessed and documented the scientific quality of the included studies;

8. used the scientific quality of the included studies appropriately in formulating conclusions, because only studies with minimal risk of bias were included (a particular issue was trial size, but conclusions were not drawn from inadequate data sets, based on previously established criteria (Moore 1998));

9. used appropriate methods to combine findings of studies and, importantly, provided analyses according to drug dose; and

10.had an appropriate or adequate conflict of interest statement.

\section{Effect of interventions}

Outcome: no worse than mild pain by 14 days

\section{Interventions for which Cochrane Reviews found no information}

None of the reviews reported finding no information. 


\section{Interventions for which Cochrane Reviews found inadequate information}

We were unable to assess our main outcome of the number reporting no worse than mild pain in seven of the nine reviews (Bao 2016; Nicholson 2017; Schmidt-Hansen 2015a; Schmidt-Hansen 2015b; Straube 2014; Wiffen 2015; Wiffen 2017c). These reviews contained fewer than 200 participants for assessment of the outcome of interest, but generally the outcome was not reported most reported a GRADE assessment of very low quality evidence.

Reported results were:

- Bao 2016: Hydromorphone - outcome not determined or poorly reported in studies; very low quality.

- Nicholson 2017: Methadone - limited data poorly reported in studies; very low quality.

- Schmidt-Hansen 2015a: Oxycodone - scores given were average pain, but most participants appeared to have achieved no worse than mild pain; very low quality.

- Schmidt-Hansen 2015b: Buprenorphine - outcome not assessed; very low quality.

- Straube 2014: Codeine - outcome not determined or poorly reported in studies; very low quality.

- Wiffen 2015: Tapentadol - outcome not determined or poorly reported in studies; no specific GRADE given.

- Wiffen 2017c: Tramadol - outcome not determined or poorly reported in studies; very low quality.

We agree with the GRADE assessments of very low quality for those that made that assessment, and consider the tapentadol review also provides very low quality evidence. We downgraded the evidence because outcomes important to people with cancer pain were not reported, providing no useful evidence, irrespective of how many people in total were involved in studies included in the review, or how small the overall risk of bias.

\section{Interventions for which Cochrane Reviews found no evidence of effect or evidence of no effect}

None of the reviews reported a null effect, although for the most part individual studies were comparing different opioids, or formulations, or doses, or dosing schedules, or a combination of these. The consequence of this was that studies or reviews had sufficient power only to determine that there was no difference within the confines of that comparison.

\section{Interventions for which Cochrane Reviews found evidence of effect, but where results were potentially subject to publication bias}

We had planned to estimate the number of participants in unpublished studies of null effect required to increase an effect size to one that was clinically irrelevant (an NNT of 10 in a comparison with placebo). Where this number was less than 400 (equivalent to four studies with 100 participants per comparison, or 50 participants per group), we considered the results to be susceptible to publication bias and therefore unreliable and indicative of lowquality evidence.

In the event there were no analyses amenable to this estimation, and so we included no studies in this category.

\section{Interventions for which Cochrane Reviews found evidence of effect, where results were reliable and not subject to potential publication bias}

Only two reviews reported on more than 200 events (Hadley 2013; Wiffen 2016). Both showed that when doses were titrated to effect, $96 \%$ of participants achieved no worse than mild pain.

- Hadley 2013: Tansdermal fentanyl - 461/479 (96\%); no GRADE assessment given.

- Wiffen 2016: Oral morphine - 362/377 (96\%); no GRADE assessment given.

We assessed this evidence as moderate quality, downgraded because of a number of minor methodological issues, including the lack of double-blinding in some studies.

Outcome: patient-reported global impression of change (PGIC)

Five reviews included PGIC as an outcome (Hadley 2013; SchmidtHansen 2015b; Straube 2014; Wiffen 2015; Wiffen 2017c). None was able to determine this outcome from any of the included studies.

We assessed this evidence as very low quality because there was no information.

\section{Outcome: withdrawals due to adverse events}

Summary table B shows the results reported for withdrawals due to adverse events and the GRADE assessments. Four reviews were unable to report on this outcome due to it being poorly or not reported in included studies (Bao 2016; Hadley 2013; Straube 2014; Wiffen 2017c).

Five of the reviews reported on withdrawals due to adverse events from at least some of the studies they included (Nicholson 2017; Schmidt-Hansen 2015a; Schmidt-Hansen 2015b; Wiffen 2015; Wiffen 2016). Adverse event withdrawal rates in the two largest data sets were 19\% (oral oxycodone) and 7\% (oral morphine), based on 513 and 154 withdrawals respectively. The other three estimates were $6 \%$ to $13 \%$, based on 12 to 52 withdrawals. Despite the low numbers of events in some reviews, there was a degree of consistency between the reviews.

GRADE estimates were of very low quality for methadone, oxycodone, and buprenorphine, and no specific GRADE estimate was made for tapentadol or morphine. We assessed this evidence as very low quality because of poor reporting of the outcome in most cases, and usually small numbers of events.

Summary table B: summary of available results on the outcome of withdrawals due to adverse events

$\begin{array}{llll}\text { Reference } & \text { Opioid } & \text { Active } & \text { GRADE }\end{array}$

(review reported)

Bao $2016 \quad$ Hydromorphone $\quad$ Not determined - poorly $\quad$ Very low

Opioids for cancer pain - an overview of Cochrane reviews (Review) 


\begin{tabular}{|c|c|c|c|}
\hline & & reported in studies & \\
\hline Hadley 2013 & Fentanyl & $\begin{array}{l}\text { Not determined - poorly } \\
\text { reported in studies }\end{array}$ & $\begin{array}{l}\text { No specific GRADE giv- } \\
\text { en }\end{array}$ \\
\hline Nicholson 2017 & Methadone & $12 / 202(6 \%)$ & Very low \\
\hline $\begin{array}{l}\text { Schmidt-Hansen } \\
2015 a\end{array}$ & Oxycodone & $513 / 2648(19 \%)$ & Very low \\
\hline $\begin{array}{l}\text { Schmidt-Hansen } \\
\text { 2015b }\end{array}$ & Buprenorphine & $52 / 443(12 \%)$ & Very low \\
\hline Straube 2014 & $\begin{array}{l}\text { Codeine with or without parac- } \\
\text { etamol }\end{array}$ & $\begin{array}{l}\text { Not determined - poorly } \\
\text { reported in studies }\end{array}$ & Very low \\
\hline Wiffen 2015 & Tapentadol & $22 / 168(13 \%)$ & $\begin{array}{l}\text { No specific GRADE giv- } \\
\text { en }\end{array}$ \\
\hline Wiffen 2016 & $\begin{array}{l}\text { Morphine instant release and } \\
\text { modified release }\end{array}$ & $154 / 2162(7 \%)$ & $\begin{array}{l}\text { No specific GRADE giv- } \\
\text { en }\end{array}$ \\
\hline Wiffen 2017c & $\begin{array}{l}\text { Tramadol with or without parac- } \\
\text { etamol }\end{array}$ & $\begin{array}{l}\text { Not determined - poorly } \\
\text { reported in studies }\end{array}$ & Very low \\
\hline
\end{tabular}

\section{Outcome: participants with at least one adverse event}

Summary table $\mathrm{C}$ shows the results reported for participants with at least one adverse event and the GRADE assessments. Six reviews were unable to report on this outcome due to it being poorly or not reported in studies (Bao 2016; Hadley 2013; Nicholson 2017; Schmidt-Hansen 2015a; Straube 2014; Wiffen 2016).

Three of the reviews reported on participants with at least one adverse event from at least some of the studies they included (Schmidt-Hansen 2015b; Wiffen 2015; Wiffen 2017c). There was little consistency in the proportion of participants reporting any adverse event, with rates above $50 \%$ for buprenorphine and tapentadol, but as low as $11 \%$ with tramadol plus paracetamol.

GRADE estimates were of very low quality apart from fentanyl, tapentadol, and morphine, for which no specific GRADE estimate was made. We assessed this evidence as very low quality because of poor reporting and small numbers of events.

\section{Summary table C: participants reporting at least one adverse} event

\begin{tabular}{llll}
\hline Reference & Opioid & Number with at least one adverse event (per cent) & GRADE \\
& & & (review reported) \\
\hline Bao 2016 & Hydromorphone & Meaningful analysis not possible due to poor reporting & Very low \\
\hline Hadley 2013 & Fentanyl & Meaningful analysis not possible due to poor reporting & $\begin{array}{l}\text { No specific GRADE } \\
\text { given }\end{array}$ \\
\hline $\begin{array}{l}\text { Nicholson 2017 } \\
\text { Schmidt-Hansen }\end{array}$ & Methadone & Meaningful analysis not possible due to poor reporting & Very low \\
\hline O15a & & Meaningful analysis not possible due to poor reporting & Very low \\
\hline $\begin{array}{l}\text { Schmidt-Hansen } \\
\text { 2015b }\end{array}$ & Buprenorphine & $152 / 264(57 \%)$ & Very low \\
\hline
\end{tabular}




\begin{tabular}{lll} 
Straube 2014 & $\begin{array}{l}\text { Codeine with or } \\
\text { without paraceta- } \\
\text { mol }\end{array}$ & Meaningful analysis not possible due to poor reporting \\
\hline Wiffen 2015 & Tapentadol & 297/386 (77\%) \\
\hline Wiffen 2016 & Morphine & Meaningful analysis not possible due to poor reporting \\
given
\end{tabular}

\section{Other outcomes}

Secondary outcomes of withdrawals due to lack of efficacy or participants experiencing any serious adverse event were not reported with any consistency (see Table D). Specific adverse events, such as thirst, reduced appetite, somnolence and dizziness, are reported in a separate review (Wiffen 2014), and we found no additional information that would require an update of that review.

\section{Summary table D: Serious adverse events and death}

\begin{tabular}{|c|c|c|c|}
\hline Reference & Opioid & Serious adverse events & Deaths \\
\hline Bao 2016 & Hydromorphone & $\begin{array}{l}\text { Not determined - poorly } \\
\text { reported in studies }\end{array}$ & No deaths in one study of 99 participants \\
\hline Hadley 2013 & Fentanyl & $\begin{array}{l}\text { Not determined - poorly } \\
\text { reported in studies }\end{array}$ & 47 deaths in 1066 participants \\
\hline Nicholson 2017 & Methadone & $12 / 202(6 \%)$ & Death uncommon, apart from one study \\
\hline $\begin{array}{l}\text { Schmidt-Hansen } \\
2015 a\end{array}$ & Oxycodone & $\begin{array}{l}\text { Not determined - poorly } \\
\text { reported in studies }\end{array}$ & $\begin{array}{l}\text { Not determined - poorly } \\
\text { reported in studies }\end{array}$ \\
\hline $\begin{array}{l}\text { Schmidt-Hansen } \\
2015 b\end{array}$ & Buprenorphine & $\begin{array}{l}\text { Not determined - poorly } \\
\text { reported in studies }\end{array}$ & $\begin{array}{l}\text { Not determined - poorly } \\
\text { reported in studies }\end{array}$ \\
\hline Straube 2014 & $\begin{array}{l}\text { Codeine with or } \\
\text { without paraceta- } \\
\text { mol }\end{array}$ & $\begin{array}{l}\text { Not determined - poorly } \\
\text { reported in studies }\end{array}$ & $\begin{array}{l}\text { Not determined - poorly } \\
\text { reported in studies }\end{array}$ \\
\hline Wiffen 2015 & Tapentadol & $22 / 168(13 \%)$ & 3 deaths in one study of 168 participants \\
\hline Wiffen 2016 & Morphine & $\begin{array}{l}\text { Not determined - poorly } \\
\text { reported in studies }\end{array}$ & $\begin{array}{l}\text { Not determined - poorly } \\
\text { reported in studies }\end{array}$ \\
\hline Wiffen 2017c & $\begin{array}{l}\text { Tramadol with or } \\
\text { without paraceta- } \\
\text { mol }\end{array}$ & $\begin{array}{l}\text { Not determined - poorly } \\
\text { reported in studies }\end{array}$ & 6 deaths in 280 participants \\
\hline
\end{tabular}




\section{DISCUSSION}

\section{Summary of main results}

Nine Cochrane Reviews examined opioids administered by various routes for treating typically moderate to severe cancer-related pain across a range of malignancies. These nine reviews had a maximum of 152 included studies and 13,524 included participants. Particular opioids investigated were buprenorphine, codeine with or without paracetamol, fentanyl, hydromorphone, methadone, morphine, oxycodone, tapentadol, and tramadol with or without paracetamol, covering the range of opioids commonly prescribed for cancer pain, at least in England (PCA 2016).

The primary outcomes of interest in this overview were the proportion of participants reporting no worse than mild pain on treatment by 14 days after start of treatment, patient global impression of change (PGIC) of much or very much improved, and withdrawals due to adverse events. This would then provide evidence to help decisions in clinical practice (Figure 1). There was limited information on these outcomes.

Only the reviews of oral morphine and transdermal fentanyl reported the important outcome for people with cancer pain of having only mild or no pain within a reasonable time (14 days) after treatment started (Moore 2013). But these two reviews demonstrated that $96 \%$ of participants achieved this outcome in a combined total of 856 participants (Hadley 2013; Wiffen 2016). Another review of oxycodone reported average pain scores that were so low that most people would have had no worse than mild pain (Schmidt-Hansen 2015a). There were no results for the PGIC outcome, and inconsistent results for the number of adverse event withdrawals, although these were always below $20 \%$. The number of participants experiencing any adverse event was inconsistently reported, and when reported occurred inconsistently, with event rates between $11 \%$ and $77 \%$.

The WHO ladder has strong opioids as the top rung of the ladder, and the evidence we have supports that position. Systematic reviews of surveys and observational studies have investigated the effectiveness of the WHO ladder and, despite using different inclusion criteria and outcomes, they tend to conclude that the range of people with cancer pain achieving 'adequate' analgesia ranges between $22 \%$ and $100 \%$ at the extremes (Azevedo São Leão Ferreira 2006; Carlson 2016; Deandrea 2008; Jadad 1995). Many individual studies show that fewer than $80 \%$ of people with cancer pain have satisfactory pain relief using the WHO ladder, which is less than the theoretical $96 \%$ or more that might be expected from the best results from oral morphine and transdermal fentanyl. The reasons for this difference between results in clinical practice and clinical trials is not known, but may include only selected populations being involved in clinical trials, and those trials often reporting a completer analysis and inadequately handling data from participants who withdraw during treatment.

\section{Overall completeness and applicability of evidence}

This overview highlights the paucity of our knowledge about the effectiveness of opioids for cancer pain. There is, of course, an understanding that most opioids are effective in managing cancer pain providing the dose is titrated to effect (with the exception of codeine and probably tramadol), but we know little from this overview about whether there are any differences in efficacy, adverse events, or effectiveness.

Studies in the reviews were typically designed to demonstrate no difference between opioids, or that a newer opioid or changed formulation may have some benefits (such as longer duration of effect, or ease of use) while maintaining a similar efficacy to a standard opioid preparation at the doses used. This led to a large number of studies examining what amounted to different drugs, and limited the possibility of any comparative analysis. What was left was essentially an analysis of randomised cohorts showing little difference between, for example, different oral morphine preparations or different transdermal fentanyl preparations.

This is not without some practical importance because it suggests that, as long as the expected pain relief follows at sensible doses, at least some opioids can be chosen for use based on convenience to the provider and the person with cancer pain, or the availability, or the cost. We can at least be sure that some, perhaps most, people treated will have adverse events; and some, probably a few, will find these intolerable and will discontinue treatment with one opioid and move to an alternative opioid.

It remains disappointing that more cannot be said, despite this moderately large number of studies and participants.

\section{Quality of the evidence}

Many, if not most, of the studies in the individual reviews had one or more elements that indicated a high risk of bias. This was often a lack of blinding, and restricting inclusion of studies to those convincingly double blind would have resulted in a significant reduction in the number of included studies. Stringent exclusion of studies with risk of bias items known to have potentially large positive bias effects in pain studies would have meant a major reduction in the number of included studies, even for some of the most recently introduced opioids.

Small size is increasingly recognised as being a major issue in studies and reviews (Fanelli 2017; Moore 1998; Nguyen 2017; Thorlund 2011), and some Cochrane Reviews have been criticised for making conclusive assessments of evidence based on inadequate information, largely or wholly from small underpowered studies (AlBalawi 2013; Brok 2009; Roberts 2015; Turner 2013). The average size of studies in the individual reviews was below 100 participants for codeine, buprenorphine, methadone, morphine, and tramadol, between 100 and 200 for hydromorphone, fentanyl, and oxycodone, and above 200 only for tapentadol. Many individual studies may therefore also have been at risk of bias because of the small size.

Some individual trial sizes were disappointingly low - as low as 11 participants at one extreme. Recent studies for the new opioid tapentadol were more realistic in size.

Reporting of adverse events was poor and inconsistent, with underpowered studies and little or no information about how the data were collected. This is disappointing, since adverse events are common with opioids, and treatment choices are frequently driven by issues of tolerability.

The majority of studies were sponsored by pharmaceutical companies and designed to show non-inferiority to instant-release morphine for modified-release morphine products, or to show 
non-inferiority (particularly to morphine) of newer potent opioids. This might be helpful for licensing and marketing purposes for pharmaceutical companies, but is of limited value in patient care. As far as we can tell there has been little investment in clinical trials from government or charities, despite the large sums spent on treating cancer pain.

Where we were able to obtain the GRADE assessment of quality of the evidence from the included reviews, it was judged to be very low. We agreed with these assessments, principally because of poor reporting, often small numbers of events, and high risk of bias on one or more items.

Very low quality means that we have very little confidence in the effect estimate; the true effect is likely to be substantially different from the estimate of effect.

\section{Potential biases in the overview process}

We are unaware of any biases in the review process. One potential bias is the overlap between authors of the overview and of some of the individual reviews. This has been addressed by having other experienced authors for the overview.

\section{Agreements and disagreements with other studies or reviews}

We are not aware of any other overviews of opioids for cancer pain for comparison.

\section{AUTHORS' CONCLUSIONS}

\section{Implications for practice}

\section{For people with cancer pain}

The amount and quality of evidence around the use of opioids for treating cancer pain is disappointingly low, although the evidence we have is that around 19 out of 20 people with moderate or severe pain who are given opioids and are able to tolerate them should have that pain reduced to mild or no pain within 14 days. This accords with the clinical experience in treating many people with cancer pain over many years. Most people will experience adverse events, and help may be needed to manage the more common undesirable adverse effects such as constipation and nausea. Perhaps 1 in 10 people treated with opioids will find these adverse events intolerable, leading to a change in treatment.

\section{For clinicians}

The amount and quality of evidence around the use of opioids for cancer pain is low. But around 95\% of people with moderate or severe pain should be able to titrate to no or only mild pain within 14 days (Wiffen 2016). This is a clinically important treatment goal judged to be valuable by patients, and probably with economic benefits to health services. Adverse events will be common, but withdrawals due to adverse events uncommon. Oral morphine remains the gold standard for treating moderate to severe cancer pain.

\section{For policy makers}

The amount and quality of evidence around the use of opioids for cancer pain is low. But around $95 \%$ of people with moderate or severe pain should be able to titrate to no or only mild pain within 14 days (Wiffen 2016). This is a clinically important treatment goal judged to be valuable by patients, and probably with economic benefits to health services. Adverse events will be common, but withdrawals due to adverse events uncommon. Oral morphine remains the gold standard for treating moderate to severe cancer pain. The WHO ladder has strong opioids as the top rung of the ladder, and the evidence we have, such as it is, supports that position; the WHO ladder is under review at the time of writing. We suggest that policy makers have a duty to ensure that opioids such as morphine are available to all who need them for treating cancer pain.

\section{For funders}

This review demonstrates that it is possible to titrate with oral morphine of any formulation, and to be confident that most patients will achieve a high level of pain relief within two weeks. There is likely to be a small number of patients who do not benefit from morphine, or who may develop intolerable adverse events, so other opioids need to be included in formularies. Oral morphine remains the gold standard for treating moderate to severe pain. The WHO ladder has strong opioids as the top rung of the ladder, and the evidence we have, such as it is, supports that position.

Opioids are tried and tested for the treatment of cancer pain. Morphine remains the first line treatment in guidelines and textbooks, although oxycodone is the major opioid in the USA. Fentanyl as a transdermal patch is widely used in higher income countries and may cause less constipation than oral opioids. Codeine has no proven role from clinical trial data in treating cancer pain.

\section{Implications for research}

\section{General}

The reviews on opioids for cancer pain reveal some major problems with our evidence. The WHO pain ladder is now over 30 years old, and remains probably the most-used and best-understood pain guidance worldwide. Despite its obvious importance there are few studies that clearly demonstrate how best to perform a study on the most important top rung relating to the treatment of moderate to severe pain.

Relatively few reviews were able to obtain data from studies that would be useful in clinical practice, namely the proportion of people with cancer having no or only mild pain within a relatively short time, for example one week after starting treatment. Many individual studies reported statistical outcomes only, rather than absolute pain intensity values. And even when absolute pain intensity values were given, they were often given as average values, rather than in terms of the number who achieved a useful degree of pain relief.

Given that many of the better-quality studies in this review were completed within the last 20 years, the obvious implication for research is to instigate an opioid trialists' collaboration in order to undertake retrospective analyses of clinical trial data, using outcomes of clear patient benefit (no worse than mild pain within two weeks of starting opioid titration), and time taken to achieve that benefit. Trialist collaborations have proved highly informative, with the Antiplatelet Trialists' Collaboration probably the largest example of how retrospective pooling and analysis of clinical trial data can lead to improvements in treatment. 


\section{Design}

Several methodological issues stand out.

The first is the use of outcomes of value to people with cancer pain. Existing trials are designed more for purposes of registration and marketing than informing and improving clinical practice, often because the outcomes chosen are average pain scores, or statistical differences, and rarely how many individuals achieve satisfactory pain relief.

The second is the time taken to achieve good pain relief. Some of the reviews - but not individual trials - have defined this as no worse than mild pain within 14 days. This allows for the needs of a titrating dose, but is within a reasonable time. Some might argue that seven days or less would be preferable, but the fact is that we do not have the data available to investigate this point, even though several better-quality and more modern studies may well have the measurements needed to elucidate it.

The third is design. Many studies had a cross-over design; even though some were relatively short there was significant attrition. Parallel group designs may be preferable.

The fourth is size. Many of the studies were very small, and, combined with cross-over design and consequent attrition, ended up reporting on very few participants. Much larger studies of at least several hundred participants are needed.

There are some other design issues that might be addressed. Most important might well be a clear decision concerning the gold-standard treatment comparator. Placebo-controlled studies in cancer pain are unlikely to be ethically feasible. In that case an effective and commonly-available therapy is the ideal common comparator in randomised trials. Oral immediate-release morphine may be that common comparator. Another is the use of prospective cohort studies rather than randomised trials. Studies could incorporate initial randomisation but a pragmatic design in order to provide immediately-relevant information on effectiveness and costs. Such designs in pain conditions have been published (Moore 2010).

\section{Measurement (endpoints)}

Trials need to consider additional endpoints of no worse than mild pain as well as the impact of opioids on symptoms that raise serious concerns such as consciousness, appetite, and thirst. The choice of measures to be used in cancer pain studies is not necessarily straightforward.

\section{ACKNOWLEDGEMENTS}

Institutional support is provided by the Oxford Pain Relief Trust.

Cochrane Review Group funding acknowledgement: this project was supported by the National Institute for Health Research, via Cochrane Infrastructure funding to the Cochrane Pain, Palliative and Supportive Care Review Group (PaPaS). The views and opinions expressed herein are those of the authors and do not necessarily reflect those of the Systematic Reviews Programme, NIHR, NHS or the Department of Health. 
RE FE RE N CES

\section{References to included reviews}

\section{Bao 2016}

Bao YJ, Hou W, Kong XY, Yang L, Xia J, Hua BJ, et al. Hydromorphone for cancer pain. Cochrane Database of Systematic Reviews 2016, Issue 10. [DOI: 10.1002/14651858.CD011108.pub2]

\section{Hadley 2013}

Hadley G, Derry S, Moore RA, Wiffen PJ. Transdermal fentanyl for cancer pain. Cochrane Database of Systematic Reviews 2013, Issue 10. [DOI: 10.1002/14651858.CD010270.pub2]

\section{Nicholson 2017}

Nicholson AB, Watson GR, Derry S, Wiffen PJ. Methadone for cancer pain. Cochrane Database of Systematic Reviews 2017, Issue 2. [DOI: 10.1002/14651858.CD003971.pub4]

\section{Schmidt-Hansen 2015a}

Schmidt-Hansen M, Bennett MI, Arnold S, Bromham N, Hilgart JS. Oxycodone for cancer-related pain. Cochrane Database of Systematic Reviews 2015, Issue 2. [DOI: 10.1002/14651858.CD003870.pub5]

\section{Schmidt-Hansen 2015b}

Schmidt-Hansen M, Bromham N, Taubert M, Arnold S, Hilgart JS. Buprenorphine for treating cancer pain. Cochrane Database of Systematic Reviews 2015, Issue 3. [DOI: 10.1002/14651858.CD009596.pub4]

\section{Straube 2014}

Straube C, Derry S, Jackson KC, Wiffen PJ, Bell RF, Strassels S, et al. Codeine, alone and with paracetamol (acetaminophen), for cancer pain. Cochrane Database of Systematic Reviews 2014, Issue 9. [DOI: 10.1002/14651858.CD006601.pub4]

\section{Wiffen 2015}

Wiffen PJ, Derry S, Naessens K, Bell RF. Oral tapentadol for cancer pain. Cochrane Database of Systematic Reviews 2015, Issue 9. [DOI: 10.1002/14651858.CD011460.pub2]

\section{Wiffen 2016}

Wiffen PJ, Wee B, Moore RA. Oral morphine for cancer pain. Cochrane Database of Systematic Reviews 2016, Issue 4. [DOI: 10.1002/14651858.CD003868.pub4]

\section{Wiffen 2017c}

Wiffen PJ, Derry S, Moore RA. Tramadol with or without paracetamol (acetaminophen) for cancer pain. Cochrane Database of Systematic Reviews 2017, Issue 1. [DOI: 10.1002/14651858.CD012508]

\section{References to excluded reviews}

\section{Wiffen 2014}

Wiffen PJ, Derry S, Moore RA. Impact of morphine, fentanyl, oxycodone or codeine on patient consciousness, appetite and thirst when used to treat cancer pain. Cochrane
Database of Systematic Reviews 2014, Issue 5. [DOI: 10.1002/14651858.CD011056.pub2]

\section{Additional references}

\section{AlBalawi 2013}

AlBalawi Z, McAlister FA, Thorlund K, Wong M, Wetterslev J. Random error in cardiovascular meta-analyses: how common are false positive and false negative results?. International Journal of Cardiology 2013;168(2):1102-7. [DOI: 10.1016/ j.ijcard.2012.11.048]

\section{Azevedo São Leão Ferreira 2006}

Azevedo São Leão Ferreira K, Kimura M, Jacobsen Teixeira M. The WHO analgesic ladder for cancer pain control, twenty years of use. How much pain relief does one get from using it? Supportive Care in Cancer 2006;14(11):1086-93. [DOI: 10.1007/ s00520-006-0086-x]

\section{Ball 1985}

Ball M, McQuay HJ, Moore RA, Allen MC, Fisher A, Sear J. Renal failure and the use of morphine in intensive care. Lancet 1985;1(8432):784-6. [DOI: 10.1016/S0140-6736(85)91448-5]

\section{Breivik 2009}

Breivik H, Cherny N, Collett B, de Conno F, Filbet M, Foubert AJ, et al. Cancer-related pain: a pan-European survey of prevalence, treatment, and patient attitudes. Annals of Oncology 2009;20(8):1420-33. [DOI: 10.1093/annonc/mdp001]

\section{Brok 2009}

Brok J, Thorlund K, Wetterslev J, Gluud C. Apparently conclusive meta-analyses may be inconclusive - trial sequential analysis adjustment of random error risk due to repetitive testing of accumulating data in apparently conclusive neonatal meta-analyses. International Journal of Epidemiology 2009;38(1):287-98. [DOI: 10.1093/ije/dyn188]

\section{Caraceni 2012}

Caraceni A, Hanks G, Kaasa S, Bennett M, Brunelli C, Cherny N, et al. for the European Palliative Research Collaborative (EPCRC), on behalf of the European Association for Palliative Care (EAPC). Use of opioid analgesics in the treatment of cancer pain: evidence-based recommendations from the EAPC. Lancet Oncology 2012;13(2):e58-68. [DOI: 10.1016/ S1470-2045(12)70040-2]

\section{Carlson 2016}

Carlson CL. Effectiveness of the World Health Organization cancer pain relief guidelines: an integrative review. Journal of Pain Research 2016;9:515-34. [DOI: 10.2147/JPR.S97759]

\section{Cascorbi 2003}

Cascorbi I. Pharmacogenetics of cytochrome P4502D6: genetic background and clinical implication. European Journal of Clinical Investigation 2003;33 (Suppl 2):17-22. [PUBMED: 14641552] 


\section{Ciszkowski 2009}

Ciszkowski C, Madadi P, Phillips MS, Lauwers AE, Koren G. Codeine, ultrarapid-metabolism genotype, and postoperative death. New England Journal of Medicine 2009;361(8):827-8. [DOI: 10.1056/NEJMc0904266]

\section{Collins 1998}

Collins SL, Faura CC, Moore RA, McQuay HJ. Peak plasma concentrations after oral morphine: a systematic review. Journal of Pain and Symptom Management 1998;16(6):388-402. [DOI: 10.1016/S0885-3924(98)00094-3]

\section{Cook 1995}

Cook RJ, Sackett DL. The number needed to treat: a clinically useful measure of treatment effect. BMJ (Clinical Research Ed.) 1995;310(6977):452-4. [DOI: 10.1136/bmj.310.6977.452]

\section{CRUK 2014}

Cancer Research UK. Cancer Statistics for the UK. www.cancerresearchuk.org/health-professional/cancerstatistics (accessed 10 April 2017).

\section{Deandrea 2008}

Deandrea S, Montanari M, Moja L, Apolone G. Prevalence of undertreatment in cancer pain. A review of published literature. Annals of Oncology 2008;19(12):1985-91. [DOI: 10.1093/annonc/ mdn419]

\section{Dechartres 2013}

Dechartres A, Trinquart L, Boutron I, Ravaud P. Influence of trial sample size on treatment effect estimates: metaepidemiological study. BMJ 2013;346:f2304. [DOI: 10.1136/ bmj.f2304]

\section{Dechartres 2014}

Dechartres A, Altman DG, Trinquart L, Boutron I, Ravaud P. Association between analytic strategy and estimates of treatment outcomes in meta-analyses. JAMA 2014;312(6):623-30. [DOI: 10.1001/jama.2014.8166]

\section{Deng 2012}

Deng D, Fu L, Zhao YX, Wu X, Zhang G, Liang C, et al. The relationship between cancer pain and quality of life in patients newly admitted to Wuhan Hospice Center of China. American Journal of Hospice \& Palliative Care 2012;29(1):53-9. [DOI: 10.1177/1049909111418636]

\section{Derry 2017}

Derry S, Wiffen PJ, Moore RA, McNicol ED, Bell RF, Carr DB, et al. Oral nonsteroidal anti-inflammatory drugs (NSAIDs) for cancer pain in adults. Cochrane Database of Systematic Reviews 2017, Issue 4. [DOI: 10.1002/14651858.CD012638]

\section{Dreidi 2016}

Dreidi MM, Hamdan-Mansour AM. Pain, sleep disturbance, and quality of life among Palestinian patients diagnosed with cancer. Journal of Cancer Education 2016;31(4):796-803. [DOI: 10.1007/s13187-015-0946-5]

\section{Dworkin 2008}

Dworkin RH, Turk DC, Wyrwich KW, Beaton D, Cleeland CS, Farrar JT, et al. Interpreting the clinical importance of treatment outcomes in chronic pain clinical trials: IMMPACT recommendations. Journal of Pain 2008;9(2):105-21. [DOI: 10.1016/j.jpain.2007.09.005]

\section{EPOC 2015}

Anon. EPOC author resources. epoc.cochrane.org/epoc-specificresources-review-authors (accessed 10 April 2017) 2015.

\section{Fallon 2011}

Fallon MT, Laird BJ. A systematic review of combination step III opioid therapy in cancer pain: an EPCRC opioid guideline project. Palliative Medicine 2011;25(5):597-603. [DOI: 10.1177/0269216310392101]

\section{Fanelli 2017}

Fanelli D, Costas R, loannidis JP. Meta-assessment of bias in science. Proceedings of the National Academy of Sciences of the USA 2017 Mar 20 [Epub ahead of print];114(14):3714-9. [DOI: 10.1073/pnas.1618569114]

\section{Faura 1996}

Faura CC, Moore RA, Horga JF, Hand CW, McQuay HJ. Morphine and morphine-6-glucuronide plasma concentrations and effect in cancer pain. Journal of Pain and Symptom Management 1996;11(2):95-102. [DOI: 10.1016/0885-3924(95)00148-4]

\section{Faura 1998}

Faura CC, Collins SL, Moore RA, McQuay HJ. Systematic review of factors affecting the ratios of morphine and its major metabolites. Pain 1998;74(1):43-53. [DOI: 10.1016/ S0304-3959(97)00142-5]

\section{Glenny 2005}

Glenny AM, Altman DG, Song F, Sakarovitch C, Deeks JJ, D'Amico R, et al. International Stroke Trial Collaborative Group. Indirect comparisons of competing interventions. Health Technology Assessment 2005;9(26):1-134, iii-iv. [DOI: 10.3310/ hta9260]

\section{Grahame-Smith 2002}

Grahame-Smith DG, Aronson JK. Oxford Textbook of Clinical Pharmacology and Drug Therapy. 3rd Edition. Oxford: Oxford University Press, 2002. [ISBN: 978-0192632340]

\section{Guyatt 2011}

Guyatt GH, Oxman AD, Kunz R, Woodcock J, Brozek J, Helfand M, et al. GRADE guidelines: 7. Rating the quality of evidence--inconsistency. Journal of Clinical Epidemiology 2011;64(12):1294-302. [DOI: 10.1016/j.jclinepi.2011.03.017]

\section{Guyatt 2013a}

Guyatt G, Oxman AD, Sultan S, Brozek J, Glasziou P, AlonsoCoello P, et al. GRADE guidelines: 11 . Making an overall rating of confidence in effect estimates for a single outcome and for all outcomes. Journal of Clinical Epidemiology 2013;66(2):151-7. [DOI: 10.1016/j.jclinepi.2012.01.006] 


\section{Guyatt 2013b}

Guyatt GH, Oxman AD, Santesso N, Helfand M, Vist G, Kunz R, et al. GRADE guidelines: 12 . Preparing summary of findings tables-binary outcomes. Journal of Clinical Epidemiology 2013;66(2):158-72. [DOI: 10.1016/j.jclinepi.2012.01.012]

\section{Higgins 2011}

Higgins JPT, Green S (editors). Cochrane Handbook for Systematic Reviews of Interventions Version 5.1.0 [updated March 2011]. The Cochrane Collaboration, 2011. Available from handbook.cochrane.org.

\section{IARC 2012}

International Agency for Research on Cancer. GLOBOCAN 2012: Estimated cancer incidence, mortality and prevalence worldwide in 2012. globocan.iarc.fr/Pages/ fact_sheets_cancer.aspx (accessed 10 April 2017).

\section{Jacox 1994}

Jacox A, Carr DB, Payne R, Berde CB, Brietbart W, Cain JM, et al. Management of Cancer Pain. Clinical Practice Guideline No. 9. AHCPR Publication No. 94-0592. Rockville, MD: Agency for Health Care Policy and Research, U.S. Department of Health and Human Services, Public Health Service, 1994.

\section{Jadad 1995}

Jadad AR, Browman GP. The WHO analgesic ladder for cancer pain management. Stepping up the quality of its evaluation. JAMA 1995;274(23):1870-3. [DOI: 10.1001/ jama.1995.03530230056031]

\section{Madadi 2007}

Madadi P, Koren G, Cairns J, Chitayat D, Gaedigk A, Leeder JS, et al. Safety of codeine during breastfeeding: fatal morphine poisoning in the breastfed neonate of a mother prescribed codeine. Canadian Family Physician Medecin de Famille Canadien 2007;53(1):33-5. [PUBMED: 17872605]

\section{Mandal 2013}

Mandal A. Morphine pharmacology. www.news-medical.net/ health/Morphine-Pharmacology.aspx (accessed 10 April 2017) Last updated 2013.

\section{Mercadante 2016}

Mercadante S, Marchetti P, Cuomo A, Mammucari M, Caraceni A, IOPS MS study Group. Breakthrough pain and its treatment: critical review and recommendations of IOPS (Italian Oncologic Pain Survey) expert group. Supportive Care in Cancer 2016;24(2):961-8. [DOI: 10.1007/s00520-015-2951-y]

\section{Miaskowski 2005}

Miaskowski C, Cleary J, Burney R, Coyne P, Finley R, Foster R, et al. Guideline for the Management of Cancer Pain in Adults and Children, APS Clinical Practice Guideline Series, No. 3. Glenview, IL: American Pain Society, 2005.

\section{Mikan 2016}

Mikan F, Wada M, Yamada M, Takahashi A, Onishi H, Ishida M, et al. The association between pain and quality of life for patients with cancer in an outpatient clinic, an inpatient oncology ward, and inpatient palliative care units. American
Journal of Hospice \& Palliative Care 2016;33(8):782-90. [DOI: 10.1177/1049909116630266]

\section{Moore 1998}

Moore RA, Gavaghan D, Tramèr MR, Collins SL, McQuay HJ. Size is everything - large amounts of information are needed to overcome random effects in estimating direction and magnitude of treatment effects. Pain 1998;78(3):209-16. [DOI: 10.1016/S0304-3959(98)00140-7]

\section{Moore 2008}

Moore RA, Barden J, Derry S, McQuay HJ. Managing potential publication bias. In: McQuay HJ, Kalso E, Moore RA editor(s). Systematic Reviews in Pain Research: Methodology Refined. Seattle: IASP Press, 2008:15-23. [ISBN: 978-0-931092-69-5]

\section{Moore 2010}

Moore RA, Derry S, McQuay HJ, Straube S, Aldington D, Wiffen P, et al. Clinical effectiveness: an approach to clinical trial design more relevant to clinical practice, acknowledging the importance of individual differences. Pain 2010;149(2):173-6. [DOI: 10.1016/j.pain.2009.08.007]

\section{Moore 2013}

Moore RA, Straube S, Aldington D. Pain measures and cut-offs - 'no worse than mild pain' as a simple, universal outcome. Anaesthesia 2013;68(4):400-12. [DOI: 10.1111/anae.12148]

\section{Moore 2014}

Moore RA, Derry S, Taylor RS, Straube S, Phillips CJ. The costs and consequences of adequately managed chronic non-cancer pain and chronic neuropathic pain. Pain Practice 2014;14(1):79-94. [DOI: 10.1111/papr.12050]

\section{Moore 2015}

Moore RA, Derry S, Aldington D, Wiffen PJ. Single dose oral analgesics for acute postoperative pain in adults - an overview of Cochrane reviews. Cochrane Database of Systematic Reviews 2015, Issue 9. [DOI: 10.1002/14651858.CD008659.pub3]

\section{Morris 1995}

Morris JA, Gardner MJ. Calculating confidence intervals for relative risk, odds ratios and standardised ratios and rates. In: Gardner MJ, Altman DG editor(s). Statistics with Confidence Confidence Intervals and Statistical Guidelines. London: British Medical Journal, 1995:50-63.

\section{Nguyen 2017}

Nguyen TL, Collins GS, Lamy A, Devereaux PJ, Daurès JP, Landais $P$, et al. Simple randomization did not protect against bias in smaller trials. Journal of Clinical Epidemiology 2017 Feb 29 [Epub ahead of print];84:105-13. [DOI: 10.1016/ j.jclinepi.2017.02.010]

\section{NICE 2016}

National Institute for Health and Care Excellence. Palliative care for adults: strong opioids for pain relief. Guideline CG140. www.nice.org.uk/guidance/cg140 2016 (accessed 10 April 2017). 


\section{Nüesch 2010}

Nüesch E, Trelle S, Reichenbach S, Rutjes AW, Tschannen B, Altman DG, et al. Small study effects in meta-analyses of osteoarthritis trials: meta-epidemiological study. BMJ 2010;341:c3515. [DOI: 10.1136/bmj.c3515]

\section{Opiates 2013}

Anon. Codeine. www.opiates.com/codeine/ (accessed 10 April 2017) 2013.

\section{Paul 1989}

Paul D, Standifer KM, Inturrisi CE, Pasternak GW. Pharmacological characterization of morphine- 6 betaglucuronide, a very potent morphine metabolite. Journal of Pharmacology and Experimental Therapeutics 1989;251(2):477-83. [PUBMED: 2810109]

\section{PCA 2016}

Prescribing \& Medicines Team. Prescription Cost Analysis England 2016. Health and Social Care Information Centre 2017 (April). [ISBN: 978-1-78386-680-9]

\section{Portenoy 1999}

Portenoy RK, Lesage P. Management of cancer pain. Lancet 1999;353(9165):1695-700. [DOI: 10.1016/ S0140-6736(99)01310-0]

\section{Prommer 2015}

Prommer EE. Pharmacological Management of Cancer-Related Pain. Cancer Control 2015;22(4):412-25. [PUBMED: 26678968]

\section{Rey 1993}

Rey R. History of Pain. Paris: Editions La Decouverte, 1993. [ISBN: 2-7071-2256-4]

\section{Ripamonti 2012a}

Ripamonti Cl, Santini D, Maranzano E, Berti M, Roila F, ESMO Guidelines Working Group. Management of cancer pain: ESMO Clinical Practice Guidelines. Annals of Oncology 2012;23 (Suppl 7):vii139-54. [DOI: 10.1093/annonc/mds233]

\section{Ripamonti 2012b}

Ripamonti Cl. Pain management. Annals of Oncology 2012;23 (Suppl 10):x294-x301. [DOI: 10.1093/annonc/mds360]

\section{Roberts 2015}

Roberts I, Ker K, Edwards P, Beecher D, Manno D, Sydenham E. The knowledge system underpinning healthcare is not fit for purpose and must change. BMJ 2015;350:h2463. [DOI: 10.1136/ bmj.h2463]

\section{Sear 1985}

Sear J, Moore A, Hunniset A, Baldwin D, Allen M, Hand C, et al. Morphine kinetics and kidney transplantation: morphine removal is influenced by renal ischemia. Anesthesia and Analgesia 1985;64(11):1065-70. [PUBMED: 3901820]

\section{Sear 1989}

Sear JW, Hand CW, Moore RA, McQuay HJ. Studies on morphine disposition: influence of renal failure on the kinetics of morphine and its metabolites. British Journal of Anaesthesia 1989;62(1):28-32. [DOI: 10.1093/bja/62.1.22]

\section{Shea 2007}

Shea BJ, Grimshaw JM, Wells GA, Boers M, Andersson N, Hamel C, et al. Development of AMSTAR: a measurement tool to assess the methodological quality of systematic reviews. BMC Medical Research Methodology 2007;7:10. [DOI: 10.1186/1471-2288-7-10]

\section{SIGN 2008}

Scottish Intercollegiate Guidelines Network. Control of pain in adults with cancer. A national clinical guideline. www.sign.ac.uk/pdf/SIGN106.pdf (accessed 10 April 2017). Edinburgh: Scottish Intercollegiate Guidelines Network, 2008.

\section{Song 2003}

Song F, Altman DG, Glenny AM, Deeks JJ. Validity of indirect comparison for estimating efficacy of competing interventions: empirical evidence from published meta-analyses. $B M J$ 2003;326(7387):472. [DOI: 10.1136/bmj.326.7387.472]

\section{Stewart 2014}

Stewart BW, Wild CP. World Cancer Report 2014. Lyon: International Agency for Research on Cancer, 2014. [ISBN: 978-92-832-0443-5]

\section{Thorlund 2011}

Thorlund K, Imberger G, Walsh M, Chu R, Gluud C, Wetterslev J, et al. The number of patients and events required to limit the risk of overestimation of intervention effects in meta-analysis-a simulation study. PLoS One 2011;6(10):e25491. [DOI: 10.1371/ journal.pone.0025491]

\section{Thornton 2000}

Thornton A, Lee P. Publication bias in meta-analysis: its causes and consequences. Journal of Clinical Epidemiology 2000;53(2):207-16. [DOI: 10.1016/S0895-4356(99)00161-4]

\section{Turner 2013}

Turner RM, Bird SM, Higgins JP. The impact of study size on meta-analyses: examination of underpowered studies in Cochrane reviews. PLOS One 2013;8(3):e59202. [DOI: 10.1371/ journal.pone.0059202]

\section{van den Beuken-van Everdingen 2016}

van den Beuken-van Everdingen MH, Hochstenbach LM, Joosten EA, Tjan-Heijnen VC, Janssen DJ. Update on prevalence of pain in patients with cancer: systematic review and meta-analysis. Journal of Pain and Symptom Management 2016;51(6):1070-90. [DOI: 10.1016/j.jpainsymman.2015.12.340]

\section{WHO 1986}

World Health Organization. Cancer Pain Relief. apps.who.int/ iris/bitstream/10665/43944/1/9241561009_eng.pdf (accessed 10 April 2017) 1986.

\section{WHO 1996}

World Health Organization. WHO Cancer Pain Relief - a Guide to Opioid Availability, 2nd Edition. apps.who.int/iris/ 
bitstream/10665/37896/1/9241544821.pdf (accessed 10 April 2017) 1996.

\section{WHO 2011}

World Health Organization. WHO Essential Medicines List. 17th list. apps.who.int/iris/bitstream/10665/70640/1/ a95053_eng.pdf (accessed 10 April 2017) 2011.

\section{Wiffen 2017a}

Wiffen PJ, Derry S, Moore RA, McNicol ED, Bell RF, Carr DB, et al. Oral paracetamol (acetaminophen) for cancer pain. Cochrane Database of Systematic Reviews 2017, Issue 4. [DOI: 10.1002/14651858.CD012637]

\section{AP PEN DICES}

\section{Appendix 1. Search strategy}

\#1 MeSH descriptor: [Pain] explode all trees (37699)

\#2 pain*:ti,ab,kw (Word variations have been searched) (103216)

\#3 \#1 or \#2 (108564)

\#4 MeSH descriptor: [Neoplasms] explode all trees (61198)

\#5 (cancer* or neoplas ${ }^{\star}$ or tumo* or carcinoma* or hodgkin* or nonhodgkin* or adenocarcinoma* or leuk? emia* or metasta* or malignan* or lymphoma* or sarcoma* or melanoma* or myeloma* or oncolog*):ti,ab,kw (Word variations have been searched) (141915)

\#6 \#4 or \#5 (145244)

\#7 MeSH descriptor: [Narcotics] this term only (808)

\#8 MeSH descriptor: [Analgesics, Opioid] explode all trees (6136)

\#9 (morphine or buprenorphine or codeine or dextromoramide or diphenoxylate or dipipanone or dextropropoxyphene or propoxyphene or diamorphine or dihydrocodeine or alfentanil or fentanyl or remifentanil or meptazinol or methadone or nalbuphine or oxycodone or papaveretum or pentazocine or meperidine or pethidine or phenazocine or hydrocodone or hydromorphone or levorphanol or oxymorphone or butorphanol or dezocine or sufentanil or ketobemidone):ti,ab,kw (Word variations have been searched) (29909)

$\# 10 \# 7$ or \#8 or \#9 (31118)

$\# 11 \# 3$ and \#6 and \#10 (1671)

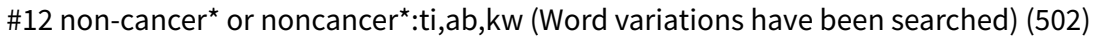

\#13 \#11 not \#12 (1169)

Limit to Cochrane Reviews (25)

\section{Appendix 2. GRADE: criteria for assigning grade of evidence}

The GRADE system uses the following criteria for assigning a quality level to a body of evidence (Chapter 12, Higgins 2011).

- High: randomised trials; or double-upgraded observational studies.

- Moderate: downgraded randomised trials; or upgraded observational studies.

- Low: double-downgraded randomised trials; or observational studies.

- Very low: triple-downgraded randomised trials; or downgraded observational studies; or case series/case reports.

Factors that may decrease the quality level of a body of evidence are:

1. limitations in the design and implementation of available studies suggesting high likelihood of bias;

2. indirectness of evidence (indirect population, intervention, control, outcomes);

3. unexplained heterogeneity or inconsistency of results (including problems with subgroup analyses);

4. imprecision of results (wide confidence intervals);

5. high probability of publication bias.

Factors that may increase the quality level of a body of evidence are:

1. large magnitude of effect;

2. all plausible confounding would reduce a demonstrated effect or suggest a spurious effect when results show no effect;
Wiffen 2017b and adolescents. Cochrane Database of Systematic Reviews 2017, Issue 2. [DOI: 10.1002/14651858.CD012564]

Wittwer E, Kern SE. Role of morphine's metabolites in analgesia: concepts and controversies. AAPS Journal 2006;8(2):E348-52.

\section{4}

Changes in trends and pattern of j.1532-2149.2014.496.x] of Pain (London, England) 2014;18(9):1343-51. [DOI: 10.1002/ 
3. dose-response gradient.

WHAT'S NEW

\begin{tabular}{lll}
\hline Date & Event & Description \\
\hline 18 February 2020 & Amended & Clarification added to Declarations of interest. \\
\hline 7 July 2017 & Review declared as stable & See Published notes. \\
\hline
\end{tabular}

\section{H I S T O R Y}

Protocol first published: Issue 3, 2017

Review first published: Issue 7, 2017

\begin{tabular}{lll}
\hline Date & Event & Description \\
\hline 28 May 2019 & Amended & Contact details updated. \\
\hline
\end{tabular}

\section{CONTRIBUTIONS OF AUTHORS}

SD, PW, and RAM drafted the protocol, and all authors contributed to the final version.

SD, PW, and RAM searched for and selected studies for inclusion and carried out data extraction.

BW and RB commented on the clinical significance and contributed to the final version.

All review authors were involved in the analysis and in writing the full review.

\section{DECLARATIONS OF INTEREST}

PW: none known.

BW: none known; BW is a specialist palliative care physician and manages patients with cancer pain.

SD: none known.

RFB: none known. RFB is a retired specialist pain physician who has worked with patients having acute, chronic or cancer pain, including palliative care patients.

RAM has received grant support from Grünenthal relating to individual patient-level analyses of trial data regarding tapentadol in osteoarthritis and back pain (2015). He has received honoraria for attending boards with Menarini concerning methods of analgesic trial design (2014), with Novartis (2014) about the design of network meta-analyses, and RB on understanding pharmacokinetics of drug uptake (2015). He has received honoraria from Omega Pharma (2016) and Futura Pharma (2016) for providing advice on trial and data analysis methods.

This review was identified in a 2019 audit as not meeting the current definition of the Cochrane Commercial Sponsorship policy. At the time of its publication it was compliant with the interpretation of the existing policy. As with all reviews, new and updated, at update this review will be revised according to 2020 policy update.

\section{SOURCES OF SUPPORT}

\section{Internal sources}

- Oxford Pain Relief Trust, UK, UK.

General institutional support 


\section{External sources}

- The National Institute for Health Research (NIHR), UK.

NIHR Cochrane Programme Grant: 13/89/29 - Addressing the unmet need of chronic pain: providing the evidence for treatments of pain.

\section{NOTES}

This overview will be assessed for updating in five years, in line with PaPaS policy for updating overview reviews.

\section{N DEX TERMS}

\section{Medical Subject Headings (MeSH)}

${ }^{*}$ Review Literature as Topic; Acetaminophen [administration \& dosage] [therapeutic use]; Administration, Cutaneous; Administration, Oral; Analgesics, Opioid [administration \& dosage] [adverse effects] [ ${ }^{\star}$ therapeutic use]; Buprenorphine [administration \& dosage] [therapeutic use]; Cancer Pain [ ${ }^{*}$ drug therapy]; Codeine [administration \& dosage] [therapeutic use]; Fentanyl [administration \& dosage] [therapeutic use]; Hydromorphone [administration \& dosage] [therapeutic use]; Methadone [administration \& dosage] [therapeutic use]; Oxycodone [administration \& dosage] [therapeutic use]; Phenols [administration \& dosage] [therapeutic use]; Tapentadol; Tramadol [administration \& dosage] [therapeutic use]

\section{MeSH check words}

Humans 